\title{
SOSIALISASI PEDOMAN GIZI SEIMBANG DENGAN METODE NUTRIEDUTAINMENT DI SDN KARAWANG WETAN 1 DAN SDN PALUMBONSARI
}

\author{
OLEH : \\ Ratih Kurniasari, Risma Rahmatunisa
}

Email : ratih.kurniasari@fkes.unsika.ac.id

\section{A. DASAR PEMIKIRAN}

Anak sekolah dasar merupakan kelompok usia rawan gizi. Hal ini disebabkan pertumbuhan anak yang pesat dan aktifitas sekolah yang padat. Agar tumbuh kembang anak dapat optimal, asupan gizi yang baik dari segi kuantitas maupun kualitas diperlukan dan perlu perhatian berbagai pihak. Pemberian gizi pada usia ini biasanya tidak berjalan secara optimal, karena banyak faktor lingkungan yang mempengaruhimya salah satu pengetahuan orang tua dan guru yang kurang sehingga menyebabkan anak tidak dapat mengkonsumsi zat gizi yang tepat. (Siti, 2012)

Indonesia pada anak umur $6-14$ tahun (Usia Sekolah) mengalami masalah gizi ganda, yaitu masalah gizi kurang dan masalah gizi lebih. Secara umum di Provinsi Jawa Barat prevalensi kurus adalah $10,9 \%$ pada laki-laki dan $8,3 \%$ pada perempuan. Sedangkan prevalensi BB lebih pada laki-laki $7,4 \%$ dan perempuan $4,6 \%$. Masalah gizi kurang umumnya disebabkan oleh kemiskinan, kurangnya persediaan pangan, kurang baiknya kualitas lingkungan, kurangnya pengetahuan masyarakat tentang gizi, menu seimbang dan kesehatan. Masalah gizi lebih disebabkan oleh kemajuan ekonomi pada lapisan masyarakat tertentu disertai dengan kurangnya pengetahuan tentang gizi, menu seimbang dan kesehatan. (Riskesdas 2017)

Pada anak usia sekolah dasar permasalahn gizi yang terjadi disebabkan oleh kurangnya pengetahuan. Pendidikan gizi merupakan suatu upaya untuk membuat seseorang atau sekelompok masyarakat sadar akan pentingnya peran gizi dalam kehidupan. Salah satu hal yang perlu diinformasikan ke anak sekolah dasar terutama masalah Pedoman Gizi Seimbang dan menyadari bahwa sebenarnya slogan Empat Sehat Lima Sempurna (4S5S) sudah tidak dipergunakan lagi (Nuryanto 2014).

Masalah gizi pada anak usia sekolah dasar dapat dicegah dengan menggunakan Pedoman Umum Gizi Seimbang (PUGS). PUGS merupakan pedoman tentang susunan makanan seharihari yang mengandung zat-zat gizi dalam jenis dan jumlah yang sesuai dengan kebutuhan tubuh, dengan memerhatikan prinsip keanekaragaman atau variasi makanan, aktivitas fisik, kebersihan, dan berat badan (BB) ideal, dengan pemilihan dan mengkonsumsi makanan yang baik, bergizi dan seimbang dapat mempengaruhi status gizi. Gizi seimbang merupakan susunan pangan sehari-hari yang mengandung zat gizi dalam jenis dan jumlah yang sesuai dengan kebutuhan tubuh. Konsumsi pangan individu dapat dipengaruhi oleh tingkat pengetahuan. Tingkat pengetahuan dapat diperoleh melalui media masa, pendidikan, pengalaman, hubungan sosial, dan budaya. Dengan tingkat pengetahuan yang baik maka sesorang akan lebih selektif dalam mengkonsumsi makanan yaitu makanan 
apa yang bagus untuk dikonsumsi, manfaat yang diberikan dan bagaimana kandungan gizi sehingga dapatan terpenuhinya kebutuhan gizi dalam tubuh (Redyastuti, 2017).

Media pendidikan gizi perlu dipertimbangkan karakteristik dan selera sasaran penyuluhan sehingga pesan gizi yang disampaikan dapat diterima secara efektif (Khomsan 2000). Pendidikan gizi yang diberikan pada anak usia sekolah dasar diupayakan diberikan melalui media yang menarik agar penyampaian materi dapat diterima lebih mudah. Edukasi gizi dapat diberikan dengan metode yang menarik, salah satunya yaitu metode nutriedutainment. Nutriedutainment merupakan gabungan dari nutrition, edukasi dan entertainment yang berarti suatu cara untuk membuat proses pendidikan dan pengajaran gizi menjadi menyenangkan, sehingga siswa dengan mudah menangkap dari pembelajaran mengenai gizi seimbang. Nutriedutainment dapat dilakukan didalam maupun diluar kelas, diberikan dengan metode melakukan

\section{E. HASIL KEGIATAN}

Pengabdian ini merupakan deskriptif komparatif untuk menguji efektifitas nutiedutainment menggunakan video, dongeng, dan kartu kwartet Pedoman Umum Gizi Seimbang dengan pre-post test. Subjek pada pengabdian ini adalah siswa sekolah dasar kelas 4 dan 5 beserta guruguru sekolah dasar tersebut. Waktu pengabdian Juni hingga Juli 2019 di SDN Karawang Wetan 1 dan SDN Palumbonsari 1.

Tahapan pelaksanaa kegiatan terbagi menjadi empat, yaitu persiapan media Nutriedutainment, perizinan kegiatan, sosialisasi Nutriedutainment di sekolah, dan evaluasi. Persiapan pengabdian masyarakat diawali dengan pembuatan permainan, mendengarkan cerita, dan menonton drama.

\section{B. TUJUAN KEGIATAN}

Tujuan dari kegiatan ini adalah meningkatnya pengetahuan pedoman gizi seimbang melalui metode nutriedutainment Di SDN Karawang Wetan 1 Dan SDN Palumbonsari

C. SASARAN KEGIATAN

Seluruh siswa Di SDN Karawang Wetan 1 Dan SDN Palumbonsari

\section{WAKTU DAN PELAKSANAAN}

Tempat pengabdian dipilih berdasarkan lokasi, sekolah terletak diantara perbatasan pusat kota Karawang dan Desa Penyangga. Berdasarkan website Kemdikbud, SDN Karawang Wetan 1 dan SDN Palumbonsari 1 telah terakreditasi A. Sehingga kedua mitra tersebut terpilih menjadi tempat pengabdian masyarakat untuk mensosialisasikan pedoman gizi seimbang dengan metode Nutriedutainment.

video mengenai pedoman gizi seimbang yang diperankan mahasiswa gizi, dongeng yang diceritakan oleh salah satu mahasiswa gizi, dan pembuatan kartu kwartet gizi seimbang. Perizinan dilakukan ke Kepala Sekolah SDN Karawang Wetan 1 dan SDN Palumbonsari $\quad 1 . \quad$ Sosialisasi Nutriedutainment dilakukan pada Juni hingga Juli 2019.

Sosialisasi Nutrieduainment dibagi menjadi tujuh sesi yaitu pengisian kuesioner pre test, penimbangan berat badan, pengukuran tinggi badan, menonton video, mendengarkan dongeng, bermain kwartet sekaligus berdiskusi mengenai Pedoman Umum Gizi Seimbang lalu 
diakhiri dengan peserta mengisi kuesioner post-test.

Evaluasi kegiatan dilakukan dengan melihat tingakt pengetahuan siswa sekolah dasar. Tingkat pengetahuan digolongkan berdasarkan skor pengetahuan yang diukur menggunakan instrument kuesioner sebelum dan sesudah Nutriedutainment. Tingkat pengetahuan dikategorikan menjadi dua yaitu dinyatakan baik jika menjawab benar $\geq 60$ ddanyatakan kurang jika memeiliki skor $<60$ (Arikunto, 2002). Tingkat pengetahuan lalu dibandingakan sebelum sosialisasi dan sesudah sosialisasi Nutriedutainment.

Kegiatan sosialisasi Nutriedutainment diawali dengan penimbangan berat badan dan pengukuran tinggi badan. Hal ini bertujuan agar siswa mengetahui salah satu pesan gizi seimbang dengan cara menjaga berat badan dan mempertahankan status gizi ke dalam ketegori normal. Setelah itu siswa mengisi kuesioner pre test.

Kegiatan Nutiedutainment dilanjutkan dengan memnonton video sekaligus mendengarkan penyuluhan dari pengabdi mengenai Pedoman Umum Gizi Seimbang. Setelah menonton dibuka sesi tanya jawab dan pertanyaan terbaik dari siswa akan mendapatkan hadiah. Hal ini membuat pembelajaran berjalan dua arah agar siswa lebih tertarik.

Setelah sesi menonton video dilanjutkan dengan mendengarkan dongeng yang dibawakan mahasiswa gizi. Dongeng menceritakan dua tokoh yang salah memliki pola hidup yang berbeda. Tokoh Kiku yang gemar olahraga dan senang makan sayur sedangkan tokoh Ciput yang senang nonton tv dan tidak suka sayur. Dongeng dibawakan dengan ceria dan melibatkan siswa dalam menirukan suarasuaranya.

Sosialisasi Nutriedutainment yang terkahir dengan media kartu kwartet gizi seimbang. Selama bermain, siswa sekaligu memperdalam kelompok bahan makanan sesuai dengan Piramida Makanan. Setiap kelompok yang terdiri dari 4 sampai 5 siswa didampingi oleh satu mahasiswa gizi yang telah dilatih dahulu untuk menyampaikan edukasi. Nutriedutainment digunakan dalam pengabdian ini ternyata memberikan dampak yang positif terhadap peningkatan pengetahuan siswa. Nutriedutainment yang terdiri dari video, dongeng dan kartu dengan warna yang mencolok memberikan daya tarik siswa untuk lebih memperhatikan materi yang disampaikan. Kegiatan pembelajaran dengan menggunakan Nutriedutainment membuat proses pembelajaran menjadi lebih menarik perhatian sehingga dapat mudah dipahami dan menyebabkan sasaran tidak menjadi cepat bosan. Hal ini dapat dilihat hasil statistic pada Tabel 1

Tabel 1. Pengetahuan Tentang Gizi Seimbang

\begin{tabular}{lccc}
\hline Kategori Pengetahuan & Baik & Kurang & \\
\hline Pre Test & 22 siswa $(23,4 \%)$ & 72 siswa $(76,6 \%)$ & $p=0.000$ \\
Post Test & 86 siswa $(91,5 \%)$ & 8 siswa $(8,5 \%)$ & \\
\hline
\end{tabular}

Peningkatan pengetahuan ini disebabkan oleh metode yang digunakan yang melibatkan edukasi gizi dan entertainment. Pemanfaatan sumber belajar yang menarik berupa media Nutriedutainment dapat meningkatkan keinginan dan minat baru, membangkitkan motivasi dan merangsang kegiatan belajar dan bahkan membawa pengaruh psikologis terhadap siswa. Penggunaan media pembelajaran dengan Nutriedutainment sangat membantu keefektifan proses 
pembelajaran dan penyampaian pesan. Selain membangkitkan motivasi dan minat siswa, media Nutriedutainment juga dapat membantu siswa meningkatkan pemahaman, menyajikan data dengan menarik dan terpercaya serta mendapatkan informasi. Media pembelajaran lebih efektif dengan melibatkan interaksi dengan seluruh media yang ditampilan.

\section{F. DAFTAR PUSTAKA}

Achadi, Pujonarti, Sudiarti, Rahmawati, Kusharisupeni, Mardatillah \& Putra. 2010. Sekolah Dasar Pintu Masuk Perbaikan Pengetahuan, Sikap, dan Perilaku Gizi Seimbang Masyarakat. Jurnal Kesehatan Masyarakat Nasional Vol. 5, No. 1, Agustus.

Arikunto S. 2002. Prosedur Penelitian suatu Pendekatan Parktek. Jakarta: Rineka Cipta.

Direktorat Jenderal Bina Gizi dan Kesehatan Ibu dan Anak. 2014. Pedoman Gizi Seimbang. Jakarta: Kementrian Kesehatan RI.

Kementerian Kesehatan RI. 2017. Laporan Hasil Riset Kesehatan Dasar (RISKESDAS). Jakarta : Balai Penelitian dan Pengembangan Kesehatan Kemenkes RI.

Khomsan A. 2000. Teknik Pengukuran Pengetahuan Gizi. Bogor: Fakultas Ekologi Manusia Institut Pertanian Bogor.

Muliani Y. 2012. Hubungan Antara Promosi Keamanan Pangan Dengan Sikap Memilih Pangan Jajanan Anak Sekolah Yang Aman. [Tesis]. Jakarta: Program Pasca Sarjana Departemen Ilmu Komunikasi Fakultas Ilmu Sosial dan Ilmu Politik Universitas Indonesia. http://lontar.ui.ac.id (Diakses pada 16 Februari 2019).

Nuryanto, N., Pramono, A., Puruhita, N., \& Muis,S. F. (2014). Pengaruh pendidikan gizi terhadap pengetahuan dan sikap tentang gizi anak Sekolah Dasar. Jurnal Gizi Indonesia, 3(1), 3236.

Profile Karawng Timur. 2017. Pemerintah Kabupaten Karawang Provinsi Jawa Barat. Diakses Online melalui https://www.karawangkab.go.id/dokumen/profile-karawang-timur.

Redyastuti E, Wijaningsih W, Jaelani. 2017. Pengetahuan dan Sikap Tentang Gizi Seimbang pada Siswa Sekolah Dasar dengan Pemberian Edukasi Gizi Menggunakan Media Komik. Jurnal Riset Gizi 5,2, 27-31.

Siti Zulaekah. 2012. Efektivitas Pendidikan Gizi dengan Media Booklet Terhadap Pengetahuan Gizi Anak SD. Jurnal Kemas 7 (2) hlm.121-128. 


\section{G. DOKUMENTASI KEGIATAN}
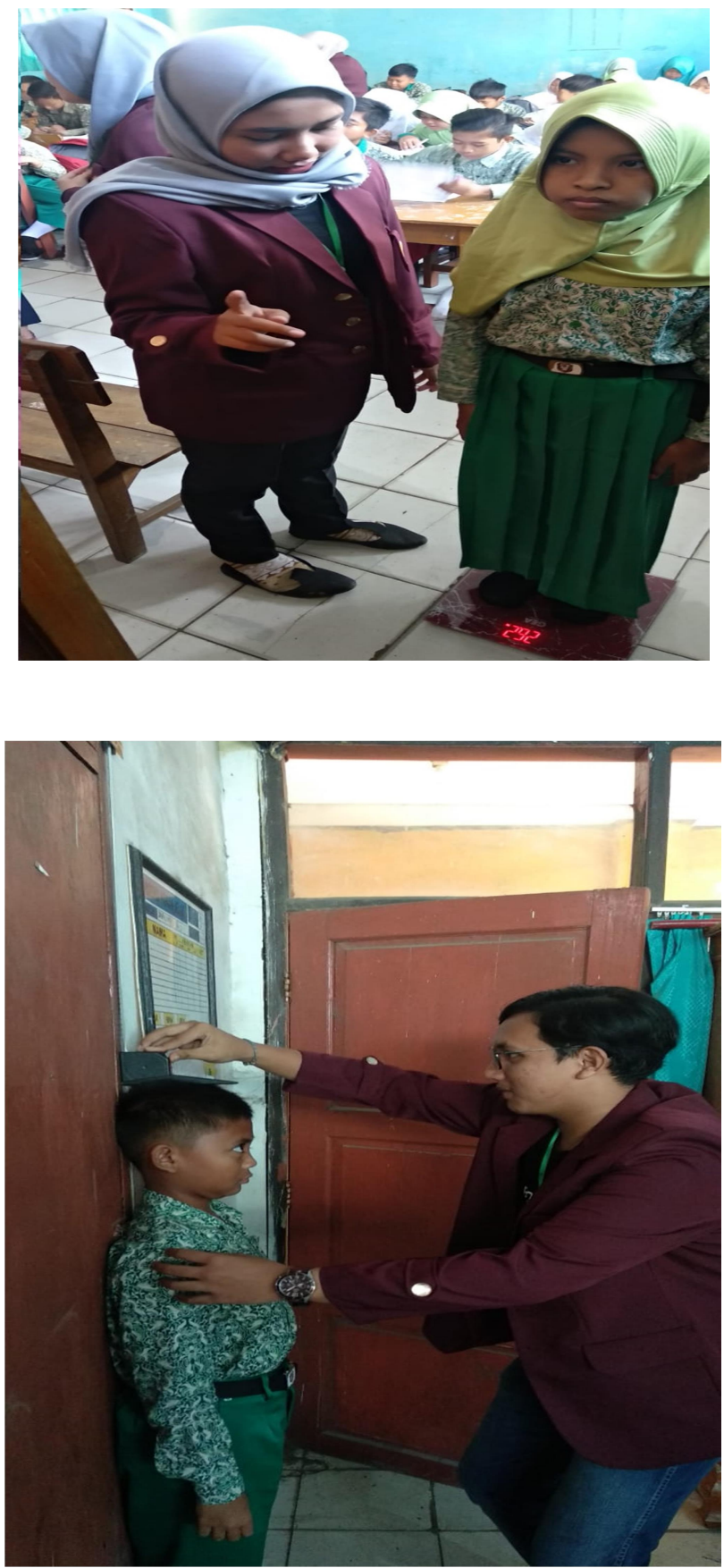

Gambar 1. Penimbangan berat badan dan pengukuran tinggi badan. 


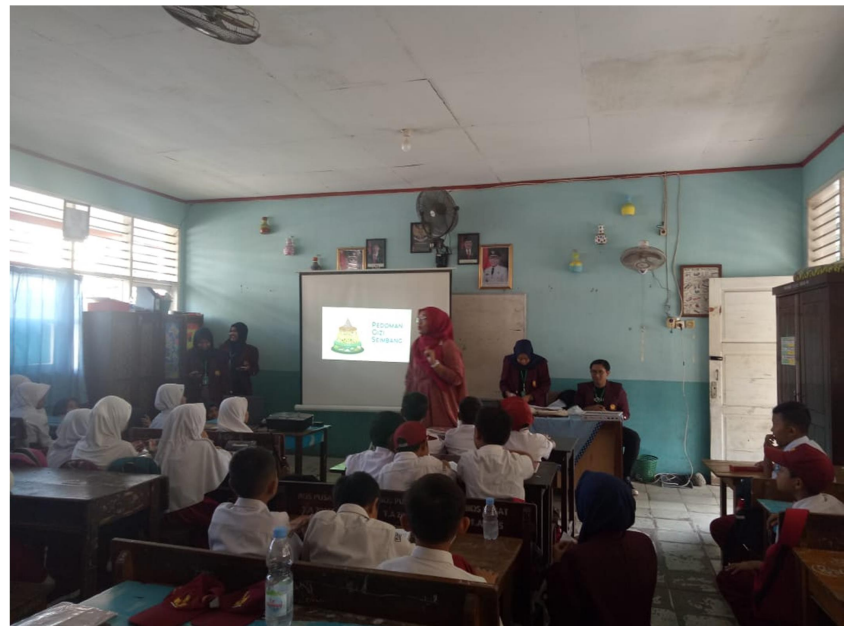

Gambar 2. Menonton video dan memberikan penyuluhan

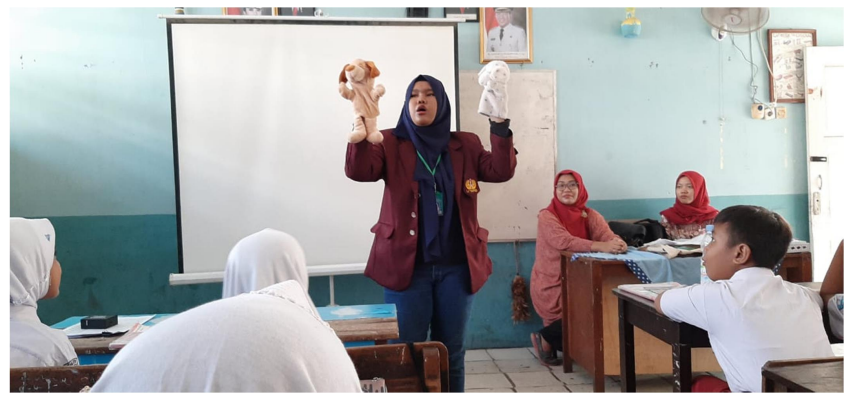

Gambar 3. Mendengarkan dongeng.

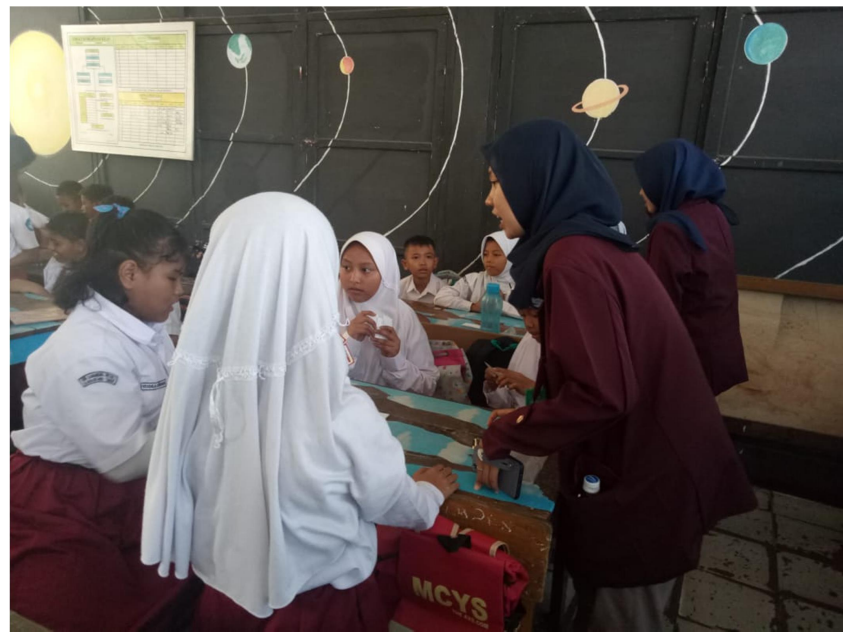

Gambar 4. Bermain kartu kwartet gizi seimbang 